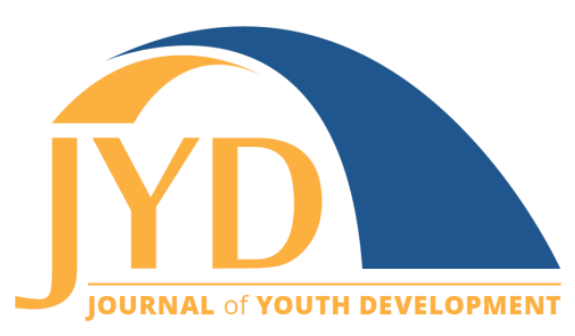

http://jyd.pitt.edu/ | Vol. 15 Issue 3 DOI 10.5195/jyd.2020.950 | ISSN 2325-4017 (online)

\title{
Fostering Healthy Mental, Emotional, and Behavioral Development through Effective Implementation and Scale-Up
}

\section{Erin Kellogg}

National Academies of Sciences, Engineering, and Medicine

ekellogg@nas.edu

\begin{abstract}
The evidence base around what causes mental, emotional, and behavioral disorders is substantial. Likewise, researchers have found methods for preventing and treating disorders, as well as for promoting healthy mental, emotional, and behavioral well-being. However, high rates of these disorders continue to persist in children and adolescents across the United States. A recent report from the National Academies of Sciences, Engineering, and Medicine entitled Fostering Healthy Mental, Emotional, and Behavioral Development in Children and Youth: A National Agenda explores updated research in epidemiology, risk and protective factors, effective strategies, and implementation science that will help diverse partners and stakeholders better support healthy mental, emotional, and behavioral development. This paper outlines the implementation science research related to programs detailed in the report and emphasizes the key components for successful intervention implementation and scale-up. It highlights the necessity of identifying core intervention components, as well as other factors such as community partnerships, implementation strategies, and the systems capacities necessary for increasing success and sustainability.
\end{abstract}

Key words: mental health, behavioral health, implementation, scale-up, development, intervention

\section{Introduction}

In the past decade, a growing body of research has significantly strengthened the scientific foundation for the United States to create a society in which young people develop the skills and health habits needed to live healthy, happy, and productive lives. The scientific basis for designing and implementing programs to support healthy mental, emotional, and behavioral (MEB) development and prevent MEB disorders is becoming clear. However, despite this

(cc) EY New articles in this journal are licensed under a Creative Commons Attribution 4.0 License. This journal is published by the University Library System, University of Pittsburgh and is cosponsored by the University of Pittsburgh Press. The Journal of Youth Development is the official peer-reviewed publication of the National Association of Extension 4-H Agents and the National AfterSchool Association. 
MEB Development: Effective Implementation and Scale-Up

scientific basis, high rates of MEB disorders continue to threaten the health and well-being of children and adolescents across the country. Half of all adolescents have had some diagnosable mental disorder, and $75 \%$ of lifetime MEB disorders first emerge at this stage of life (National Institute of Mental Health, 2019). Anxiety disorders are the most common MEB disorders among children and adolescents (31.0\%), followed by behavior disorders $(19.1 \%)$, depression $(14.3 \%)$, and substance disorders (11.4\%). Moreover, rates of depression, suicide, and selfharm among young people have been increasing: in 2015, suicide was the second most common cause of death among young people ages 15 to 25 and the third most common among those ages 10 to 14 (Olfson, 2018).

MEB disorders are a growing burden for affected young people, their families, and the communities in which they live. They hinder young people's development into healthy and "economically productive and engaged citizens" (Center for the Study of Social Policy, 2012, p. 4), and in 2015 accounted for the highest rates of disability in the U.S. population (Kamal, 2017). U.S. spending on mental illness was estimated at $\$ 89$ billion in 2013 , but mental illness is also associated with loss of earning and productivity and other indirect costs (Kamal, 2017). Furthermore, youth without a diagnosable MEB disorder do not necessarily experience positive mental health development. Researchers have begun to examine flourishing in children, defined as positive MEB development independent of the presence or absence of an MEB disorder. A recent study estimated that fewer than half (40.3\%) of children in the U.S. met the criteria for flourishing (Bethell et al., 2019).

A recent report from the National Academies of Sciences, Engineering, and Medicine (NASEM) entitled Fostering Healthy Mental, Emotional, and Behavioral Development in Children and Youth: A National Agenda (NASEM, 2019) ${ }^{1}$ explores why high rates of MEB disorders and low rates of flourishing persist, despite scientific understanding of risk and promotive factors. The report discusses updated research in epidemiology, risk and protective factors, and effective education, health care, and policy strategies for healthy MEB development in children. It also

\footnotetext{
${ }^{1}$ This article reproduces text verbatim and paraphrases Fostering Healthy Mental, Emotional, Behavioral Developing in Children and Youth: A National Agenda released in 2019 and used with permission from the National Academies Press, Washington, DC. Suggested citation for the full report: National Academies of Sciences, Engineering, and Medicine. 2019. Fostering Healthy Mental, Emotional, and Behavioral Development in Children and Youth: A National Agenda. Washington, DC: The National Academies Press.

https://doi.org/10.17226/25201. The report was authored by the Committee on Fostering Healthy Mental, Emotional, and Behavioral Development Among Children and Youth. Appreciation goes to William Aldridge, II, Rico Catalano, Natacha Blain, and Kelly Kelleher for their reviews of earlier drafts of this article. This study was funded by the Centers for Disease Control and Prevention; the National Institutes of Health, National Center for Complementary and Integrative Health; the National Institute on Drug Abuse; and the Substance Abuse and Mental Health Services Administration.
} 
highlights implementation science, and its application to the promotion of healthy MEB development in children and youth through interventions and programs. In the past decade, researchers have significantly expanded understanding of what is necessary for effective implementation of strategies to promote MEB health and prevent MEB disorders. This body of work has started to yield a fuller picture of what effective implementation entails and shows that adoption of evidence-based programs and faithful adherence to program protocols are necessary but not sufficient for population-level impact.

\section{Understanding Effective Implementation}

The purpose of careful implementation is to take initiatives from the research stage into widespread practice in a way that ensures fidelity to the original program design (Fixsen et al., 2009). Effectively implementing a program on a broad scale is a process that takes time and requires ongoing evaluation and adaptation to local circumstance (Aarons et al., 2011; Metz \& Bartley, 2012; Meyers et al., 2012). During the past decade, implementation research has focused on both the foundations that support the process and the process itself. Thus, the term scale-up refers to systematic ways of increasing the reach and sustainability of an intervention (Ilott et al., 2013).

Researchers have refined the definition of implementation as a complex process for ensuring not only the elements essential to making a program work but also an iterative process used to optimize the program so it can yield its intended benefits as it is scaled up. Implementation and scale-up are increasingly understood as context dependent processes that rely on core sets of partners, strategies, and capacities, rather than generalized processes easily applied to various settings. Researchers have worked on adaptive program design methods to identify core intervention components, as well as methods for appropriate program adaptation. Implementation strategies have been developed and are now being used in practice to test ways of addressing barriers of implementation. Additionally, the partnerships and system capacities needed to support and sustain implementation and scale-up outcomes are now better understood, moving past the elements of training, materials, funding, and evaluation.

\section{Identifying and Monitoring the Fidelity of Core Components}

Effective implementation of an intervention begins with the identification of its core components, or the variables that are essential for a program to function as designed. Identifying core components makes it possible to implement a program with fidelity, which is associated with program effectiveness. Additionally, understanding core components allows for 
the adaptation of the nonessential components of an intervention to meet context-specific needs (Fixsen et al., 2013). ${ }^{2}$

Ideally, program developers will begin identifying its core components during the program design phase, and then monitor the role played by these components throughout efficacy and effectiveness trials. This process is often supported by mediation research, which entails looking for factors that explain how the core components actually operate.

\section{Studying Mediating Factors}

Mediation studies typically choose one or two of many possible mediating mechanisms to examine. Researchers studying mediating factors in family- and school-based interventions have explored a variety of child and adolescent intervention outcomes, including effects on child conduct problems, school achievement, and depression and anxiety symptoms (Carreras et al., 2016). Others have explored core skills and intervention targets, such as positive parenting (Bjørknes et al., 2012; Gardner et al. , 2006; Tein et al., 2006) and social-emotional character development (Bavarian et al., 2016).

\section{Pinning Down Core Components}

The studies of mediation show how the operation of core theoretical constructs can be established and how specific components of an intervention influence long-term outcomes. However, the results of such studies provide less evidence about which components are essential for intervention effectiveness, and which can be adapted or dropped based on community context.

Methods for disentangling potentially influential factors could provide evidence on which intervention components are necessary to produce desired effects on youth outcomes, and which can be removed to streamline the intervention (Collins, 2014; Collins et al., 2007; Danaher \& Seeley, 2009; Lindquist et al., 2007). Disentangling complex mediating constructs may also help identify causal mechanisms for the intervention. An example of such an approach is the Multiphase Optimization Strategy (MOST), which uses a three-step process based on engineering principles (Collins \& Kugler, 2018; Collins et al., 2005). In the first step, experimental methods are used to assess an array of delivery components. Next, experiments

2 It should be noted that what is required for effective implementation of programs and interventions is not necessarily what is required for effective implementation of policies. While the consensus report touches on both topics, this paper will explore implementation science as it specifically relates to programs and interventions. 
are used to confirm the identification of core components. Lastly, efficacy and effectiveness are confirmed in randomized control trials. Other work has also used trials of intervention components to identify those that are essential, beginning with a thorough evaluation of a single multicomponent intervention (Collins, 2014; Collins et al., 2007; Danaher \& Seeley, 2009; Lindquist et al., 2007; Mohr et al., 2015). An alternative approach, the sequential mediation study, explores the operation of an intervention over time to examine the complex pathways involving mediating factors (Deković et al., 2012; Sandler et al., 2011).

\section{Monitoring Fidelity}

Once core components have been identified, monitoring the fidelity of their implementation within a program is critical. Although the value of quality monitoring has long been recognized, it is often neglected due the increased burden it requires. However, without data to suggest whether a program has been implemented with fidelity, it is impossible to know whether or not outcomes can be attributed to the program itself (Fixsen et al., 2013).

Blase and Fixsen (2013) make several suggestions for how stakeholders can support the delivery of core intervention components before or during implementation and scaling efforts:

- Researchers should identify, measure, and test the efficacy of core program components.

- Funders should include the specification of core components among project deliverables to support both demonstration or pilot testing and quality assurance and improvement efforts.

- Decision makers for program adoption should include among program selection criteria (a) a clear description of core program components; (b) clarity on how core components are connected with expanded program outcomes; (c) fidelity assessment tools that are feasible, reliable, and valid; and (d) monitoring mechanisms in place to provide feedback for improvement to program implementers.

- Program disseminators should provide fidelity assessment resources or capabilities with which to monitor the presence of core components during implementation, and clearly comment on potential detriments to intended outcomes when fidelity is low.

\section{Choosing and Adapting Programs for Local Communities}

Although identifying core components of an intervention is crucial, evidence also emphasizes that programs are more effective when they are responsive to local needs, preferences, and capacities (Horner et al., 2014; Walker et al., 2015). The diversity of communities across the 
United States makes it clear that context-specific intervention adaptation is necessary, particularly given the disparities in access to care and outcomes for minority populations and those who live in under-resourced communities (Alegria et al., 2015; Alegria et al., 2010; Coker et al., 2009).

Research shows that adapting programs for cultural groups while maintaining core components has yielded significant benefits (National Research Council [NRC] \& Institute of Medicine [IOM], 2009). Culturally sensitive interventions include content that is welcoming to the target population, is not offensive, and comes across as familiar to the program participants (NRC \& IOM, 2009). To date, there is limited research on cultural, racial, and ethnic concerns related to intervention adaptation. However, adaptation is most likely to be effective when it is based on evidence that aligns with the program goals and theory (Aarons et al., 2012; Castro \& Yasui, 2017; Chambers et al., 2013; Durlak \& DuPre, 2008; Moore et al., 2013).

\section{Frameworks for Cultural Adaptation}

Realizing the importance of cultural adaptation in intervention scale-up, researchers have developed several frameworks for doing so. One such example is the Ecological Validity Model, which describes eight dimensions to be considered: language, persons, metaphors, content, concepts, goals, methods, and context (Bernal et al., 1995). Another example is ADAPT-ITT, a process framework for steps in adaptation, such as assessment to understand the target population, pretesting, consultation with topical experts, and pilot testing (Wingood \& DiClemente, 2008). Other research differentiates between surface adaptations, which involve superficial aspects of an intervention, and deep structural adaptations that relate to content and affect outcomes of interest more directly (Moore et al., 2013; Resnicow et al., 2000).

Despite this thinking about what is important in adapting programs to meet the needs of diverse communities, the findings around the effects of cultural adaptations on treatment outcomes suggests that results have been mixed (Benish et al., 2011; Gonzales, 2017; Griner \& Smith, 2006; Huey \& Polo, 2008). Such findings indicate that while surface adaptations may be necessary to make interventions culturally sensitive, more rigorous research is needed to determine whether deep adaptations are also needed.

\section{Community Engagement}

Research on how to adapt programs to effectively serve diverse populations increasingly emphasizes the importance of direct community engagement. For MEB interventions, this may 
be done by engaging community health workers in the delivery of the interventions. Such workers are often from the same community as the program participants, and thus can serve as experts on that population. This approach has been effective in a variety of settings and for a variety of target problems (Barnett et al., 2018).

An alternative to the adaptation of an existing intervention is to design a program based on the real-world needs and cultures of a specific community (Marsiglia \& Kulis, 2009). This approach, known as practice-based evidence, draws on culturally specific practices and reflects the beliefs and values of the local community (Isaacs et al., 2005). While these initiatives may be accepted as effective by the community, most reflect only surface-level cultural specifics, such as services provided in other languages, rather than deep-content characteristics that reflect cultural values (Lyon et al., 2017).

\section{Implementation Strategies}

Implementation strategies are those methods and tools used to change policies, administrative procedures, and environments. They are the means through which core intervention components are put into practice. The recent evolution of implementation science has included an expanded focus on identifying, classifying, and studying these basic elements of the implementation process (Proctor et al., 2013). These strategies can be discrete-single actions or processes, or blended-combining several discrete strategies.

\section{Discrete Implementation Strategies}

Discrete strategies serve an array of purposes, including engaging program participants, building relationships with other stakeholders, supporting practitioners, and providing interactive assistance or training (Powell et al., 2017). These often act as the basis for more complex strategies, described below. However, the evidence base on discrete strategies is still limited. Few such strategies have been tested for their individual contributions to effectiveness, and researchers are beginning to move from asking whether they work, to asking instead: how, why, where, and for whom they work (Baker et al., 2015). Thus, more research is needed to improve understanding of the potential impact of discrete implementation strategies.

\section{Blended Implementation Strategies}

Blended implementation strategies combine several discrete strategies to address broad implementation challenges (Powell et al., 2012; Spoth et al., 2013). Such challenges are often 
complex, such as increasing local readiness and enhancing program quality (Chinman et al., 2015; Hawkins et al., 2002). Examples of successful blended implementation strategies which have been developed and tested to assist in sustainably implementing MEB health programs include Communities That Care, Promoting School-Community-University Partnership to Enhance Resilience (PROSPER), and Getting to Outcomes (NASEM, 2019).

\section{Implementation Support}

External implementation support can enhance the capacity of agencies, coalitions, and communities to carry out interventions. Providers of this support work directly within organizational and system environments to ensure the success and sustainability of program implementation and scale-up. It is commonly paid for by funders of program scale-up (e.g., state and federal service administrators, private foundations), although it may be paid for directly by program adopters (i.e., those organizations implementing and delivering the program). Successful blended implementation strategies often include the provision of external support in the form of training and technical assistance for program facilitators (Meyers et al., 2012).

External implementation support also plays a key role in optimizing local implementation outcomes (Berta et al., 2015; Blase, 2009; Chinman et al., 2016; Katz \& Wandersman, 2016; Rushovich et al., 2015; Spoth \& Greenberg, 2011; West et al., 2012). For examples, studies of the PROSPER model revealed that collaborations with external providers of technical support was associated with high participant recruitment and stronger functioning of community prevention teams (Chilenski et al., 2016; Spoth, Clair et al., 2007). Similar work in other contexts reinforces these findings (Fagan \& Mihalic, 2003; Leeman et al., 2015; Romney et al., 2014; West et al., 2012), although research has not yet determined an optimal dosage of implementation support (Beam et al., 2012; Chinman et al., 2016; Feinberg, 2008; Spoth et al., 2007).

\section{A Model of System Capacity}

Large-scale implementation requires more than a well-researched program design with clear core components and an effective strategy. It also requires invested partners and system capacity-organizational infrastructure, resources, and abilities - to deliver it to a broad population and sustain the intervention over time. Researchers have developed a range of implementation models, frameworks, and strategies (Tabak et al., 2012; Waltz et al., 2015). 
One such model, described in the recent National Academies report (NASEM, 2019), is described in this paper.

The theory of change presented in Figure 1 depicts a model of essential partners, capacities, and processes that are necessary for an intervention to achieve sustained benefits at a population level. Co-creation partners each contribute in a different way, but collectively support the development of system capacity for intervention implementation and scale-up. In this model, the system optimizes outcomes by collecting information about initial results and then supports adaptation of infrastructure and practices as necessary. Information is collected on feasibility, fidelity, cost, and participant engagement (Proctor et al., 2011). As the system becomes operational, attention shifts to outcomes at the individual, family, school, and community levels, and modifications are made to optimize these outcomes. The ultimate objective is intervention improvement that is evident in population-level indicators.

Figure 1. Integrated theory of change for the successful, sustainable scale-up of evidence-based interventions.

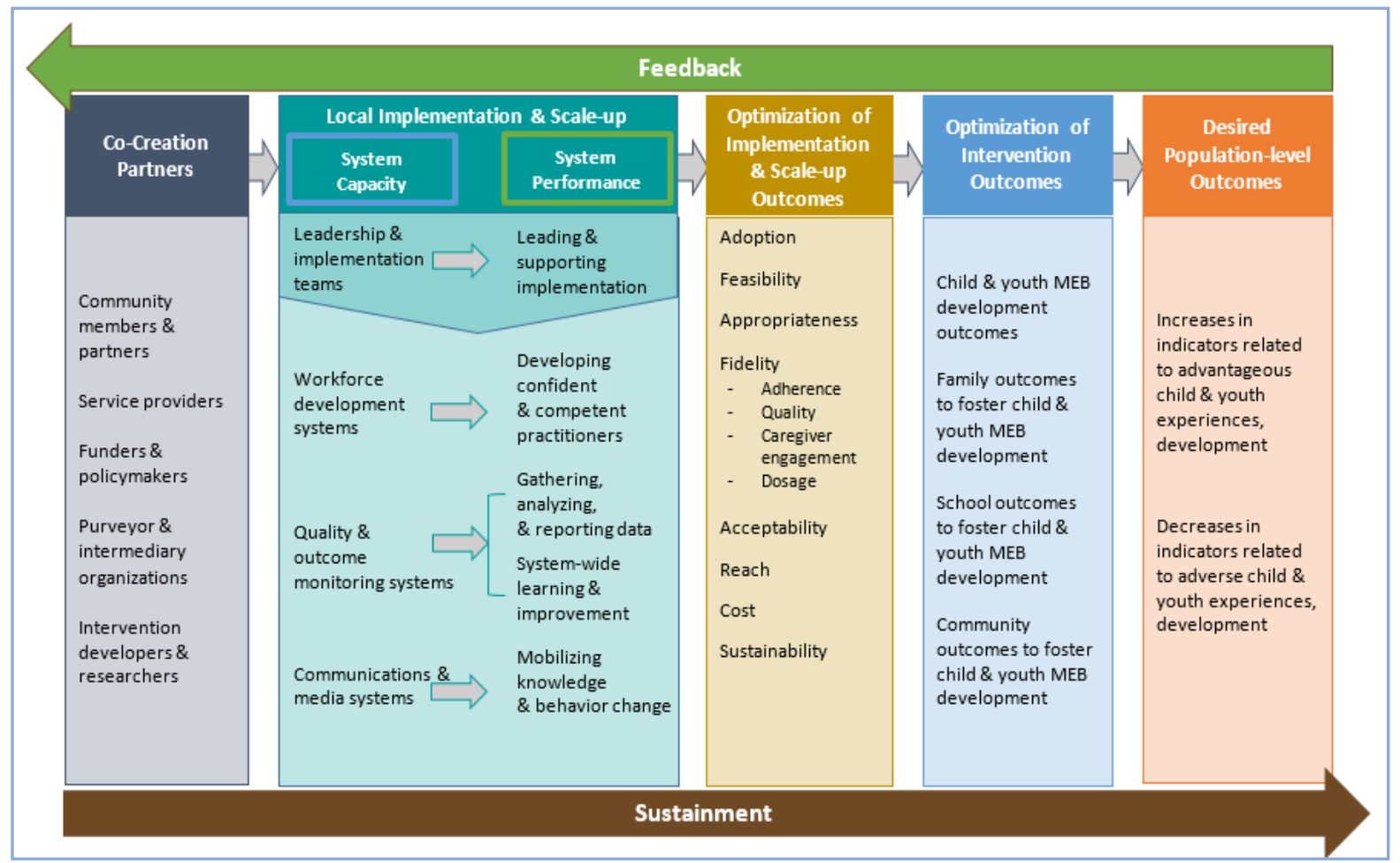

Note. Adapted from Aldridge, Boothroyd, Veazey et al., (2016) and Chinman et al. (2016). 


\section{MEB Development: Effective Implementation and Scale-Up}

This system is a feedback loop in which practitioners and researchers collect data at any or all points of the change process and use that data to continuously improve the intervention design and implementation.

\section{Co-Creation Partners}

The term "co-creation" is used to describe partners who are closely involved in both the identification of the problem and its solution. Co-creation partners work in coordination with each other and with program goals (Metz, 2015; Metz et al., 2014; Pfitzer et al., 2013; Voorberg et al., 2015). While there is limited evidence on the direct outcomes of co-creation, the importance of each of the partners is clear.

\section{Community Members}

As co-creation partners, community members are those most likely to benefit directly or indirectly from the implementation and scale-up of an intervention. This group may include individuals and families who participate in the program and other community stakeholders who see positive impacts from improved outcomes of the program participants. Best practices for five key functions that community members may play in the development of system capacity have been identified (Boothroyd et al., 2017):

1. Relationship building

2. Addressing system barriers

3. Establishing culturally relevant supports and services

4. Meaningful involvement in implementation

5. Ongoing communication and feedback for continuous improvement

Community members may also be partners in research or other efforts that support effective program implementation (Deverka et al., 2012; Graham et al., 2016; Lavallee et al., 2012). While seeking community input can slow the process and may add complexity, it is essential for true collaboration and program sustainability (Barnes and Schmitz, 2016; Boothroyd et al., 2017).

\section{Service Providers}

Service providers include leaders, managers, supervisors, and practitioners who have a stake in the adoption, implementation, and outcomes of a program. This group plays at least two key roles. First, practitioners and supervisors may have a unique perspective on program fit, 


\section{MEB Development: Effective Implementation and Scale-Up}

delivery, and reception for the population with which they work. Their direct work with the program may enable them to see things that are missed by leaders and external partners. Second, the readiness of service providers to adapt and respond—or "buy in"—when a new program is implemented is critical to its success (Dymnicki et al., 2014). Additional work has also pointed to the importance of strong organizational leadership, communication, and openness to trying new programs (Chilenski et al., 2015; Romney et al., 2014).

\section{Funders and Policy Makers}

Both funders and policy makers are essential to creating a hospitable environment for a sustainable program. Policy strategies at the service provider, state agency, policy, and social levels show promise (Powell et al., 2016). However, research has found little benefit from strict mandates that use top-down approaches in program implementation. Instead, developing broad political support by engaging multiple stakeholders is the approach most likely to succeed (Powell et al., 2016; Willging et al., 2015).

\section{Purveyors and Intermediary Organizations}

Purveyors are those who provide training and technical assistance for program implementers and supporters, usually through a close relationship with the program's developer (Fixsen et al., 2005). Their interactions with service providers may be formal interactions addressing program guidelines, adherence, training, and supervision; they may also be informal interactions addressing personal and professional issues outside the scope of primary work efforts (Palinkas et al., 2009). Factors that promote effective interactions between service providers and purveyors include accessibility, mutual respect, a shared language, and a willingness to engage in compromise (McWilliam et al., 2016; Schoenwald \& Henggeler, 2003; Webster-Stratton et al., 2014).

Whereas purveyors typically represent a single program, intermediaries support a wider range of programs (Mettrick et al., 2015). These are often housed within universities or nonprofit organizations and take their direction from state and local governments. Their functions may include providing support in the identification of promising programs and service delivery models; assisting in workforce development activities; and providing expertise in policy and financing (Mettrick et al., 2015). 


\section{MEB Development: Effective Implementation and Scale-Up}

\section{Intervention developers and researchers}

Individuals and organizations that conduct research needed to create or improve the design of a program clearly have an essential role, as do those who carry out the continued work of supporting and scaling-up a program.

Research has also started to explore the value of partnerships between researchers and other stakeholders. Such a collaboration creates opportunity for translation of field evidence to program improvements (Chambers et al., 2013). An ongoing process of development, evaluation, and refinement promotes program effectiveness as long as that process is supported by shared access to information (Chambers \& Azrin, 2013).

\section{Key Elements of Capacity for Scale-Up}

Several elements support effective implementation of a program at scale, including leadership and implementation teams, workforce development systems, quality and outcome monitoring systems, and communications and media systems.

\section{Leadership and Implementation Teams}

Collaboration is needed at multiple levels, both within and among leadership and implementation teams and broader community coalitions. Local leadership and implementation teams design and lead an organization-wide strategy for bringing about a targeted change (Higgins et al., 2012). These teams act as change agents inside the organization and ensure that core components of a program are successfully carried out (Aldridge, Boothroyd, Fleming et al., 2016). The most successful implementation teams include individuals who have decisionmaking authority within the organization, some level of oversight on program delivery, and capacity to engage stakeholders to create a supportive climate (Meyers et al., 2012). Research has also found that several features of organizational or system leadership can contribute to successful program implementation: setting a project mission and vision, planning for program sustainment early and often, setting realistic program plans, and having alternative strategies for program survival (Aarons et al., 2016). Studies have also identified additional roles played by leadership, such as championing the program and marketing it to stakeholders; institutionalizing the program through a combination of funding, contracting, and improvement plans, and fostering multilevel collaboration among state, county, and community stakeholders (Aarons et al., 2016). 


\section{MEB Development: Effective Implementation and Scale-Up}

For large-scale programs, leaders and implementation teams may be linked within a community coalition. This is usually a formal alliance of local organizations and individuals that work to address a community issue collectively. A community coalition can serve as a hub for integrating and coordinating efforts, facilitating communication, and mutually reinforcing activities (Billioux et al., 2017; Hanleybrown et al., 2012). The development of such a coalition can be a strategy for aligning leadership, implementation teams, and other system partners in cross-sector community environments (Hawkins et al., 2002; Spoth \& Greenberg, 2011). Community coalitions are most successful when they include elements such as community readiness, training and fidelity to the coalition process, formalized rules, skilled leadership models, membership diversity, leveraging of funding sources, and increases in capacity (Brown et al., 2010; Brown et al., 2015; Feinberg, Bontempo, \& Greenberg, 2008; Feinberg et al., 2014; Feinberg et al., 2002; Gomez et al., 2005; Johnson et al., 2017; Zakocs \& Guckenburg, 2007; Zakocs \& Edwards, 2006).

In some cases, these collaborations are supported by learning collaboratives. These are made up of independent programs with similar goals. Learning collaboratives have demonstrated success in joint planning, as well as experimentation in implementing, testing, and improving programs across a range of sites. Sharing of knowledge within a learning collaborative offers the opportunity to accelerate the development and dissemination of effective programs. Strong leadership, open sharing between participants, and developed infrastructure are crucial for the success of a learning collaborative.

\section{Workforce development systems}

The effectiveness of any program to foster healthy MEB development will depend on a welltrained workforce. However, both a shortage of individuals choosing this field and a lack of professional development are barriers (IOM \& NRC, 2015).

Program developers frequently specify criteria for recruitment and selection of workers based on the professional qualifications and experience necessary for delivering the core components of an intervention. However, peer counselors, parenting counselors, and community health workers are able to supplement some of the intervention work. These members of the workforce bring varied training and are often deeply connected to the communities in which they work (Boat et al., 2016). 
While many program purveyors provide training and materials as a foundational learning experience, it is important that training be closely aligned with the core program components. Basic training strategies such as workshops, reading of treatment manuals, and brief supervision have not been shown to produce adequate training outcomes for practitioners (Beidas \& Kendall, 2010; Herschell et al., 2010). Effective training usually involves active learning in a multidisciplinary and well-supervised setting with frequent evaluation and two-way feedback (Beidas \& Kendall, 2010).

Ongoing coaching and supervision are also key to maintaining an effective workforce. For example, continuing training can be particularly valuable when it occurs close to the time when new skills are to be put into practice (Nadeem et al., 2013). Emphasizing skill building, problem solving related to implementation barriers, and planning for how to sustain the trained skills are also crucial aspects (Nadeem et al., 2013). Coaching and training can be effective if they target specific skills and link those skills to direct applications (Joyce \& Showers, 2002). Supporting coaching environments and quality feedback are associated with favorable outcomes related not only to intervention fidelity, but also practitioner turnover (Aarons, Fettes, et al., 2009; Aarons, Sommerfeld, et al., 2009).

\section{Quality and outcome monitoring systems}

The collection of information about quality and outcomes is vital to the continuous improvement in implementation and scale-up. Quality monitoring systems collect data on the implementation outcomes noted in Figure 1, including fidelity, reach, cost, and sustainability. Monitoring an array of outcomes helps to determine if benchmarks are being met and can give early indication of community-level outcomes.

Community monitoring systems that collect information about the health and well-being of children and youth can also be useful tools for public health. Such systems identify the existence of problems, their effects, trends in incidence, and the results of interventions (Rivara \& Johnston, 2013). They provide data that can be used to prioritize needs, select evidencebased programs, and monitor program results.

The Society for Prevention Research has described the key features of successful community monitoring systems (Mrazek et al., 2004, p. iv):

1. Provides the community with accurate estimates of well-being for the entire population of children and adolescents. 
2. Encourages widespread participation of community members in the design, maintenance, and use of the system.

3. Identifies key factors of well-being shown by research to be important, including measures of youth functioning and of the factors influencing development.

4. Integrates all available data, both survey-based and archival (routinely collected record data from various systems).

5. Generates information for decision makers and community members that is easy to understand and readily usable to answer specific questions.

6. Provides timely data about trends in well-being and in risk and protective factors that predict youth outcomes.

7. Provides the basis for priority setting and decision-making regarding choices of programs, policies, and practices to improve youth well-being.

\section{Communications and Media Systems}

Research suggests that mass media has the potential to contribute to efforts both to strengthen prosocial behavior and to prevent MEB problems in families and schools. Both radio- and TVbased media campaigns may influence individuals' decisions about their behaviors (Wakefield et al., 2010). They may also have indirect effects through the influence of people directly exposed to the campaign on others not exposed, and by increasing support for norms and public policies (Wakefield et al., 2010). Campaigns appear to have increased effectiveness when products and services to support health behavior change are available through community-based programs, as well as when policies are in place to support the behavior change.

\section{Conclusion}

Over the past decade, research has shed new light on essential aspects of program implementation and scale-up. The effectiveness of an intervention intended to prevent MEB disorders or promote healthy MEB development depends on careful identification of the core components that are essential for its effectiveness. Once those core components are identified, nonessential elements of a program can be adapted so that the intervention meets the contextspecific needs of a community. Engaging communities in the adaptation of nonessential components will increase the likelihood of success for the program. Blended implementation strategies that involve external support can help build necessary capacities and optimize local implementation outcomes. 
While core components and effective implementation strategies are essential, they are not enough to ensure effective intervention implementation and scale-up. A range of partners including community members, service providers, funders, policy makers, purveyors, intermediary organizations, and researchers is also crucial. These stakeholders must work together to develop and operate within a complex system that makes implementation and scale-up possible. Organizational infrastructure is also necessary. Elements of this include strong leadership and implementation teams; workforce development; monitoring and data systems; and media campaigns, particularly for population-level impact.

Overall, effective implementation of a well-researched program to foster healthy MEB development at scale depends on an interactive system that provides the capacity to implement and continuously improve the program. When this new understanding of the complexities involved in implementation and scale-up is applied in practice, interventions will be able to better address the high rates of MEB disorders and promote healthy MEB development in children and youth.

\section{References}

Aarons, G. A. A., Fettes, D. L., Flores, L. E., Jr., \& Sommerfeld, D. H. (2009). Evidence-based practice implementation and staff emotional exhaustion in childrens' services. Behaviour Research and Therapy, 4711), 954-960. https://doi.org/10.1016/j.brat.2009.07.006

Aarons, G. A., Green, A. E., Palinkas, L. A., Self-Brown, S., Whitaker, D. J., Lutzker, J. R., Silovsky, J. F., Hecht, D. B., \& Chaffin, M. J. (2012). Dynamic adaptation process to implement an evidencebased child maltreatment intervention. Implementation Sciences, 7, 32.

https://doi.org/10.1186/1748-5908-7-32

Aarons, G. A., Green, A. E., Trott, E., Willging, C. E., Torres, E. M., Ehrhart, M. G., \& Roesch, S. C. (2016). The roles of system and organizational leadership in system-wide evidence-based intervention sustainment: A mixed-method study. Administration and Policy in Mental Health, 43(6), 991-1008. https://doi.org/10.1007\%2Fs10488-016-0751-4

Aarons, G. A., Hurlburt, M., \& Horwitz, S. M. (2011). Advancing a conceptual model of evidence-based practice implementation in public service sectors. Administration and Policy in Mental Health and Mental Health Services Research, 38(1), 4-23. https://dx.doi.org/10.1007\%2Fs10488-010-0327-7

Aarons, G. A., Sommerfeld, D. H., Hecht, D. B., Silovsky, J. F., \& Chaffin, M. J. (2009). The impact of evidence-based practice implementation and fidelity monitoring on staff turnover: Evidence for a protective effect. Journal of Consulting and Clinical Psychology, 77(2), 270-280. https://dx.doi.org/10.1037\%2Fa0013223 
Journal of Youth Development | http://jyd.pitt.edu/ | Vol. 15 Issue 3 DOI 10.5195/jyd.2020.950 MEB Development: Effective Implementation and Scale-Up

Aldridge, W. A., II, Boothroyd, R. I., Fleming, W. O., Lofts Jarboe, K., Morrow, J., Ritchie, G. F., \& Sebian, J. (2016). Transforming community prevention systems for sustained impact: Embedding active implementation and scaling functions. Translational Behavioral Medicine, 6(1), 135-144. https://doi.org/10.1007/s13142-015-0351-y

Aldridge, W. A., II, Boothroyd, R. I., Veazey, C. A., Powell, B. J., Murray, D. W., \& Prinz, R. J. (2016). Ensuring active implementation support for North Carolina counties scaling the Triple P system of interventions. Frank Porter Graham Child Development Institute, University of North Carolina at Chapel Hill.

Alegria, M., Green, J. G., McLaughlin, K., \& Loder, S. (2015). Disparities in child and adolescent mental health and mental health services in the U.S.

https://philanthropynewyork.org/sites/default/files/resources/Disparities in child and adolescent health.pdf

Alegria, M., Vallas, M., \& Pumariega, A. J. (2010). Racial and ethnic disparities in pediatric mental health. Child and Adolescent Psychiatric Clinics of North America, 19(4), 759-774. https://dx.doi.org/10.1016\%2Fj.chc.2010.07.001

Baker, R., Camosso-Stefinovic, J., Gillies, C., Shaw, E. J., Cheater, F., Flottorp, S., Robertson, N., Wensing, M., Fiander, M., Eccles, M. P., Godycki-Cwirko, M., van Lieshout, J., \& Jager, C. (2015). Tailored interventions to address determinants of practice. Cochrane Database of Systematic Reviews, Apr 29(4):c0005470. https://doi.org/10.1002/14651858.CD005470.pub3

Barnes, M., \& Schmitz, P. (2016). Community engagement matters (now more than ever). Stanford Social Innovation Review, 16.

https://ssir.org/articles/entry/community engagement matters now more than ever

Barnett, M. L., Gonzalez, A., Miranda, J., Chavira, D. A., \& Lau, A. S. (2018). Mobilizing community health workers to address mental health disparities for underserved populations: A systematic review. Administration and Policy in Mental Health and Mental Health Services Research, 45(2), 195-211. https://dx.doi.org/10.1007\%2Fs10488-017-0815-0

Bavarian, N., Lewis, K. M., Acock, A., DuBois, D. L., Yan, Z., Vuchinich, S., Silverthorn, N., Day, J., \& Flay, B. R. (2016). Effects of a school-based social-emotional and character development program on health behaviors: A matched-pair, cluster-randomized controlled trial. The Journal of Primary Prevention, 371), 87-105. https://doi.org/10.1007/s10935-016-0417-8

Beam, M., Ehrlich, G., Black, J. D., Block, A., \& Leviton, L. C. (2012). Evaluation of the healthy schools program: Part II. The role of technical assistance. Preventing Chronic Disease, 9, E64. https://dx.doi.org/10.5888\%2Fpcd9.110105

Beidas, R. S., \& Kendall, P. C. (2010). Training therapists in evidence-based practice: A critical review of studies from a systems-contextual perspective. Clinical Psychology: Science and Practice, 171), 1-30. https://doi.org/10.1111/j.1468-2850.2009.01187.x 
Benish, S. G., Quintana, S., \& Wampold, B. E. (2011). Culturally adapted psychotherapy and the legitimacy of myth: A direct-comparison meta-analysis. Journal of Counseling Psychology, 58(3), 279-289. https://doi.org/10.1037/a0023626

Bernal, G., Bonilla, J., \& Bellido, C. (1995). Ecological validity and cultural sensitivity for outcome research: Issues for the cultural adaptation and development of psychosocial treatments with Hispanics. Journal of Abnormal Child Psychology, 23(1), 67-82. https://doi.org/10.1007/BF01447045

Berta, W., Cranley, L., Dearing, J., Dogherty, E., Squires, J., \& Estabrooks, C. (2015). Why (we think) facilitation works: Insights from organizational learning theory. Implementation Science, 10(141). https://doi.org/10.1186/s13012-015-0323-0

Bethell, C. D., Gombojav, N., \& Whitaker, R. C. (2019). Family resilience and connection promote flourishing among U.S. children, even amid adversity. Health Affairs, 38(5), 729-737. https://doi.org/10.1377/hlthaff.2018.05425

Billioux, A., Conway, P. H., \& Alley, D. E. (2017). Addressing population health: Integrators in the accountable health communities model. Journal of the American Medical Association, 318(19), 1865-1866. https://doi.org/10.1001/jama.2017.15063

Bjørknes, R., Kjøbli, J., Manger, T., \& Jakobsen, R. (2012). Parent training among ethnic minorities: Parenting practices as mediators of change in child conduct problems. Family Relations, 61(1), 101-114. https://doi.org/10.1111/j.1741-3729.2011.00683.x

Blase, K., \& Fixsen, D. (2013). Core intervention components identifying and operationalizing what makes programs work. ASPE research brief.

Blase, K. A. (2009). Technical assistance to promote service and system change. Roadmap to effective intervention practices \#4. University of South Florida, Technical Assistance Center on Social Emotional Intervention for Young Children.

Boat, T. F., Land, M. L., Leslie, L. K., Hoagwood, K. E., Hawkins-Walsh, E., McCabe, M. A., Fraser, M. W., de Saxe Zerden, L., Lombardi, B. M., Fritz, G. K., Kiyoe Frogner, B. , Hawkins, J. D., \& Sweeney, M. (2016). Workforce development to enhance the cognitive, affective, and behavioral health of children and youth: Opportunities and barriers in child health care training. NAM Perspectives. Discussion Paper, National Academy of Medicine. https://doi.org/ 10.31478/201611b

Boothroyd, R. I., Flint, A. Y., Lapiz, A. M., Lyons, S., Jarboe, K. L., \& Aldridge, W. A., $2^{\text {nd }}$. (2017). Active involved community partnerships: Co-creating implementation infrastructure for getting to and sustaining social impact. Translational Behavioral Medicine, 73), 467-477. https://doi.org/10.1007/s13142-017-0503-3

Brown, L. D., Feinberg, M. E., \& Greenberg, M. T. (2010). Determinants of community coalition ability to support evidence-based programs. Prevention Science, 11(3), 287-297. 
Journal of Youth Development | http://jyd.pitt.edu/ | Vol. 15 Issue 3 DOI 10.5195/jyd.2020.950 MEB Development: Effective Implementation and Scale-Up

Brown, L. D., Feinberg, M. E., Shapiro, V. B., \& Greenberg, M. T. (2015). Reciprocal relations between coalition functioning and the provision of implementation support. Prevention Science, 16(1),101109. https://doi.org/10.1007/s11121-013-0447-x

Carreras, G., Bosi, S., Angelini, P., \& Gorini, G. (2016). Mediating factors of a school-based multicomponent smoking prevention intervention: The LDP cluster randomized controlled trial. Health Education Research, 31(4), 439-449. https://doi.org/10.1093/her/cyw031

Castro, F. G., \& Yasui, M. (2017). Advances in EBI development for diverse populations: Towards a science of intervention adaptation. Prevention Science, 18(6), 623-629. https://doi.org/10.1007/s11121-017-0809-x

Center for the Study of Social Policy. (2012). Results-based public policy strategies for promoting children's social, emotional and behavioral health. Author. https://www.healthymarriageandfamilies.org/sites/default/files/Resource\%20Files/PromoteChildrens-Social-Emotional-and-Behavioral-Health 1.pdf

Chambers, D. A., \& Azrin, S. T. (2013). Research and services partnerships: Partnership: A fundamental component of dissemination and implementation research. Psychiatric Services, 64(6), 509-511. https://doi.org/10.1176/appi.ps.201300032

Chambers, D. A., Glasgow, R. E., \& Stange, K. C. (2013). The dynamic sustainability framework: Addressing the paradox of sustainment amid ongoing change. Implementation Science, 8, 117. https://doi.org/10.1186/1748-5908-8-117

Chilenski, S. M., Olson, J. R., Schulte, J. A., Perkins, D. F., \& Spoth, R. (2015). A multi-level examination of how the organizational context relates to readiness to implement prevention and evidencebased programming in community settings. Evaluation and Program Planning, 48, 63-74. https://doi.org/10.1016/j.evalprogplan.2014.10.004

Chilenski, S. M., Perkins, D. F., Olson, J., Hoffman, L., Feinberg, M. E., Greenberg, M., Welsh, J., Crowley, D. M., \& Spoth, R. (2016). The power of a collaborative relationship between technical assistance providers and community prevention teams: A correlational and longitudinal study. Evaluation and Program Planning, 54, 19-29. https://doi.org/10.1016/j.evalprogplan.2015.10.002

Chinman, M., Acosta, J., Ebener, P., Malone, P. S., \& Slaughter, M. (2015). A novel test of the GTO implementation support intervention in low resource settings: Year 1 findings and challenges. Implementation Science, 10(S1), A34. https://doi.org/10.1186/1748-5908-10-S1-A34

Chinman, M., Acosta, J. D., Ebener, P. A., Sigel, C., \& Keith, J. (2016). Getting To Outcomes $®$ guide for teen pregnancy prevention. Available: https://www.rand.org/content/dam/rand/pubs/tools/TL100/TL199/RAND_TL199.pdf

Coker, T. R., Elliott, M. N., Kataoka, S., Schwebel, D. C., Mrug, S., Grunbaum, J. A., Cuccaro, P., Peskin, M. F., \& Schuster, M. A. (2009). Racial/ethnic disparities in the mental health care utilization of fifth grade children. Academic Pediatrics, 9(2), 89-96. https://doi.org/10.1016/j.acap.2008.11.007 
Collins, L. M. (2014). Optimizing family intervention programs: The multiphase optimization strategy (MOST). In S. McHale, P. Amato, \& A. Booth (Eds.), Emerging methods in family research (pp. 231-244). Cham, Switzerland: Springer. https://doi.org/10.1007/978-3-319-01562-0 14

Collins, L. M., \& Kugler, K. C. (2018). Optimization of behavioral, biobehavioral, and biomedical interventions: Advanced topics. The Pennsylvania State University.

Collins, L. M., Murphy, S. A., Nair, V. N., \& Strecher, V. J. (2005). A strategy for optimizing and evaluating behavioral interventions. Annals of Behavioral Medicine, 30(1), 65-73. https://doi.org/10.1207/s15324796abm3001_8

Collins, L. M., Murphy, S. A., \& Strecher, V. (2007). The multiphase optimization strategy (MOST) and the sequential multiple assignment randomized trial (SMART): New methods for more potent ehealth interventions. American Journal of Preventive Medicine, 32(5 Suppl.), 112-118. https://doi.org/10.1016/j.amepre.2007.01.022

Danaher, B. G., \& Seeley, J. R. (2009). Methodological issues in research on web-based behavioral interventions. Annals of Behavioral Medicine, 38(1), 28-39. https://doi.org/10.1007/s12160-009$\underline{9129-0}$

Deković, M., Asscher, J. J., Manders, W. A., Prins, P. J., \& van der Laan, P. (2012). Within-intervention change: Mediators of intervention effects during multisystemic therapy. Journal of Consulting and Clinical Psychology, 80(4), 574-587. https://doi.org/10.1037/a0028482

Deverka, P. A., Lavallee, D. C., Desai, P. J., Esmail, L. C., Ramsey, S. D., Veenstra, D. L., \& Tunis, S. R. (2012). Stakeholder participation in comparative effectiveness research: Defining a framework for effective engagement. Journal of Comparative Effectiveness Research, 1(2), 181-194. https://doi.org/10.2217/cer.12.7

Durlak, J. A., \& DuPre, E. P. (2008). Implementation matters: A review of research on the influence of implementation on program outcomes and the factors affecting implementation. American Journal of Community Psychology, 41(3-4), 327-350. https://doi.org/10.1007/s10464-008-9165-0

Dymnicki, A. B., Wandersman, A., Osher, D., Grigorescu, V., \& Huang, L. (2014). Willing, able -> ready: Basics and policy implications of readiness as a key component for implementation of evidencebased interventions. Office of the Assistant Secretary for Planning and Evaluation, Office of Human Services Policy, U.S. Department of Health and Human Services. https://aspe.hhs.gov/report/willing-able-ready-basics-and-policy-implications-readiness-keycomponent-scaling-implementation-evidence-based-interventions

Fagan, A. A., \& Mihalic, S. (2003). Strategies for enhancing the adoption of school-based prevention programs: Lessons learned from the blueprints for violence prevention replications of the Life Skills Training Program. Journal of Community Psychology, 31(3), 235-253. https://doi.org/10.1002/jcop.10045 
Journal of Youth Development | http://jyd.pitt.edu/ | Vol. 15 Issue 3 DOI 10.5195/jyd.2020.950

MEB Development: Effective Implementation and Scale-Up

Feinberg, M. E., Bontempo, D. E., \& Greenberg, M. T. (2008). Predictors and level of sustainability of community prevention coalitions. American Journal of Preventive Medicine, 34(6), 495-501. https://doi.org/10.1016/j.amepre.2008.01.030

Feinberg, M. E., Greenberg, M. T., \& Osgood, D. W. (2004). Readiness, functioning, and perceived effectiveness in community prevention coalitions: A study of Communities That Care. American Journal of Community Psychology, 33(3-4), 163-176.

https://doi.org/10.1023/B:AJCP.0000027003.75394.2b

Feinberg, M. E., Greenberg, M. T., Osgood, D. W., Anderson, A., \& Babinski, L. (2002). The effects of training community leaders in prevention science: Communities That Care in Pennsylvania. Evaluation and Program Planning, 25(3), 245-259. https://doi.org/10.1016/S01497189(02)00019-8

Feinberg, M. E., Ridenour, T. A., \& Greenberg, M. T. (2008). The longitudinal effect of technical assistance dosage on the functioning of communities that care prevention boards in Pennsylvania. The Journal of Primary Prevention, 29(2), 145-165.

https://doi.org/10.1007/s10935-008-0130-3

Fixsen, D. L., Blase, K., Metz, A., \& van Dyke, M. (2013). Statewide implementation of evidence-based programs. Exceptional Children, 79(2), 213-230. https://doi.org/10.1177/001440291307900206

Fixsen, D. L., Blase, K. A., Naoom, S. F., \& Wallace, F. (2009). Core implementation components. Research on Social Work Practice, 19(5), 531-540. https://doi.org/10.1177/1049731509335549

Fixsen, D. L., Naoom, S. F., Blase, K. A., Friedman, R. M., \& Wallace, F. (2005). Implementation research: A synthesis of the literature. (Publication No. 231). University of South Florida, Louis de la Parte Florida Mental Health Institute, National Implementation Research Network.

Gardner, F., Burton, J., \& Klimes, I. (2006). Randomised controlled trial of a parenting intervention in the voluntary sector for reducing child conduct problems: Outcomes and mechanisms of change. Journal of Child Psychology and Psychiatry, 47(11), 1123-1132. https://doi.org/10.1111/j.14697610.2006.01668.x

Gomez, B. J., Greenberg, M. T., \& Feinberg, M. E. (2005). Sustainability of community coalitions: An evaluation of communities that care. Prevention Science, 6(3), 199-202.

\section{https://doi.org/10.1007/s11121-005-0003-4}

Gonzales, N. A. (2017). Expanding the cultural adaptation framework for population-level impact. Prevention Science, 18(6), 689-693.

Graham, P. W., Kim, M. M., Clinton-Sherrod, A. M., Yaros, A., Richmond, A. N., Jackson, M., \& CorbieSmith, G. (2016). What is the role of culture, diversity, and community engagement in transdisciplinary translational science? Translational Behavioral Medicine: Practice, Policy, Research 6(1), 115-124. https://doi.org/10.1007/s13142-015-0368-2 
Journal of Youth Development | http://jyd.pitt.edu/ | Vol. 15 Issue 3 DOI 10.5195/jyd.2020.950 MEB Development: Effective Implementation and Scale-Up

Griner, D., \& Smith, T. B. (2006). Culturally adapted mental health intervention: A meta-analytic review. Psychotherapy (Chicago, Illinois), 43(4), 531-548. https://doi.org/10.1037/0033-3204.43.4.531

Hanleybrown, F., Kania, J., \& Kramer, M. R. (2012). Channeling change: Making collective impact work. https://www.iowacollegeaid.Gov/sites/default/files/D.\%20Channeling Change Article\%202.pdf

Hawkins, J. D., Catalano, R. F., \& Arthur, M. W. (2002). Promoting science-based prevention in communities. Addictive Behaviors, 27(6), 951-976. https://doi.org/10.1016/S03064603(02)00298-8

Herschell, A. D., Kolko, D. J., Baumann, B. L., \& Davis, A. C. (2010). The role of therapist training in the implementation of psychosocial treatments: A review and critique with recommendations. Clinical Psychology Review, 30(4), 448-466. https://doi.org/10.1016/j.cpr.2010.02.005

Higgins, M. C., Weiner, J., \& Young, L. (2012). Implementation teams: A new lever for organizational change. Journal of Organizational Behavior, 33(3), 366-388. https://doi.org/10.1002/job.1773

Horner, R. H., Blitz, C., \& Ross, S. W. (2014). The importance of contextual fit when implementing evidence-based interventions. Washington, DC: Office of the Assistant Secretary for Planning and Evaluation, Office of Human Services Policy, U.S. Department of Health and Human Services.

Huey, S. J., Jr., \& Polo, A. J. (2008). Evidence-based psychosocial treatments for ethnic minority youth. Journal of Clinical Child \& Adolescent Psychology, 371), 262-301. https://doi.org/10.1080/15374410701820174

Ilott, I., Gerrish, K., Pownall, S., Eltringham, S., \& Booth, A. (2013). Exploring scale-up, spread, and sustainability: An instrumental case study tracing an innovation to enhance dysphagia care. Implementation Science, 8(1), 1-7. https://doi.org/10.1186/1748-5908-8-128

Institute of Medicine \& National Research Council. (2015). Transforming the workforce for children birth through age 8: A unifying foundation. Washington, DC: The National Academies Press. https://doi.org/10.17226/19401

Isaacs, M. R., Huang, L., Hernandez, M., \& Echo-Hawk, H. (2005). The road to evidence: The intersection of evidence-based practices and cultural competence in children's mental health. https://pdfs. semanticscholar.org/4b1c/cbbda9c76b8006b95de5ec03ee2c5938e847.pdf? ga=2.19 $\underline{669438.782938303 .1564325298-559765494.1564325298}$

Johnson, K., Collins, D., Shamblen, S., Kenworthy, T., \& Wandersman, A. (2017). Long-term sustainability of evidence-based prevention interventions and community coalitions survival: A five and onehalf year follow-up study. Prevention Science, 18(5), 610-621. https://doi.org/10.1007/s11121$\underline{017-0784-2}$

Joyce, B. R., \& Showers, B. (2002). Student achievement through staff development (3 ${ }^{\text {rd }}$ ed.). Association for Supervision and Curriculum Development.

Kamal, R. (2017). What are the current costs and outcomes related to mental health and substance abuse disorders? Peterson-Kaiser Health System Tracker. 
Journal of Youth Development | http://jyd.pitt.edu/ | Vol. 15 Issue 3 DOI 10.5195/jyd.2020.950

MEB Development: Effective Implementation and Scale-Up

https://www.Healthsystemtracker.org/chart-collection/current-costs-outcomes-related-mentalhealth-substance-abuse-disorders/\#item-disease-burden-alcohol-use-disorders-higher-average-u$\underline{\mathrm{s}}$

Katz, J., \& Wandersman, A. (2016). Technical assistance to enhance prevention capacity: A research synthesis of the evidence base. Prevention Science, 17(4), 417-428.

https://doi.org/10.1007/s11121-016-0636-5

Lavallee, D. C., Williams, C. J., Tambor, E. S., \& Deverka, P. A. (2012). Stakeholder engagement in comparative effectiveness research: How will we measure success? Journal of Comparative Effectiveness Research, 1(5), 397-407. https://doi.org/10.2217/cer.12.44

Leeman, J., Calancie, L., Hartman, M. A., Escoffery, C. T., Herrmann, A. K., Tague, L. E., Moore, A. A., Wilson, K. M., Schreiner, M., \& Samuel-Hodge, C. (2015). What strategies are used to build practitioners' capacity to implement community-based interventions and are they effective?: A systematic review. Implementation Science, 1O(1). https://doi.org/10.1186/s13012-015-0272-7

Lindquist, R., Wyman, J. F., Talley, K. M., Findorff, M. J., \& Gross, C. R. (2007). Design of control-group conditions in clinical trials of behavioral interventions. Journal of Nursing Scholarship, 39(3), 214221. https://doi.org/10.1111/j.1547-5069.2007.00171.x

Lyon, A. R., Pullmann, M. D., Walker, S. C., \& D’Angelo, G. (2017). Community-sourced intervention programs: Review of submissions in response to a statewide call for "promising practices." Administration and Policy in Mental Health, 44(1), 16-28. https://doi.org/10.1007/s10488-015$\underline{0650-0}$

Marsiglia, F. F., \& Kulis, S. S. (2009). Diversity, oppression, and change: Culturally grounded social work. Lyceum Books.

McWilliam, J., Brown, J., Sanders, M. R., \& Jones, L. (2016). The Triple P Implementation Framework: The role of purveyors in the implementation and sustainability of evidence-based programs. Prevention Science, 175), 636-645. https://doi.org/10.1007/s11121-016-0661-4

Mettrick, J., Harburger, D. S., Kanary, P. J., Lieman, R. B., \& Zabel, M. (2015). Building cross-system implementation centers: $A$ roadmap for state and local child serving agencies in developing Centers of Excellence (COE). The Institute for Innovation and Implementation, University of Maryland.

Metz, A. (2015). Implementation brief: The potential of co-creation in implementation science. National Implementation Research Network.

https://nirn.fpg.unc.edu/sites/nirn.fpg.unc.edu/files/resources/NIRN-Metz-ImplementationBreifCoCreation.pdf

Metz, A., Albers, B., \& Albers, B. (2014). What does it take? How federal initiatives can support the implementation of evidence-based programs to improve outcomes for adolescents. Journal of Adolescent Health, 54(Suppl. 3), s92-S96. 
Metz, A., \& Bartley, L. (2012). Active implementation frameworks for program success: How to use implementation science to improve outcomes for children. Zero to Three Journal, 32(4), 11-18.

Meyers, D. C., Durlak, J. A., \& Wandersman, A. (2012). The quality implementation framework: A synthesis of critical steps in the implementation process. American Journal of Community Psychology, 50(3-4), 462-480. https://doi.org/10.1007/s10464-012-9522-x

Mohr, D. C., Schueller, S. M., Riley, W. T., Brown, C. H., Cuijpers, P., Duan, N., Kwasny, M. J., StilesShields, C., \& Cheung, K. (2015). Trials of intervention principles: Evaluation methods for evolving behavioral intervention technologies. Journal of Medical Internet Research, 177), e166. https://doi.org/10.2196/jmir.4391

Moore, J. E., Bumbarger, B. K., \& Cooper, B. R. (2013). Examining adaptations of evidence-based programs in natural contexts. Journal of Primary Prevention, 34(3), 147-161.

\section{https://doi.org/10.1007/s10935-013-0303-6}

Mrazek, P. B., Biglan, A., \& Hawkins, J. D. (2004). Community-monitoring systems: Tracking and improving the well-being of America's children and adolescents. Society for Prevention Research.

Nadeem, E., Gleacher, A., \& Beidas, R. S. (2013). Consultation as an implementation strategy for evidence-based practices across multiple contexts: Unpacking the black box. Administration and Policy in Mental Health and Mental Health Services Research, 40(6), 439-450. https://doi.org/10.1007/s10488-013-0502-8

National Academies of Sciences, Engineering, and Medicine. (2019). Fostering Healthy Mental, Emotional, and Behavioral Development in Children and Youth: A National Agenda. Washington, DC: The National Academies Press. https://doi.org/10.17226/25201

National Institute of Mental Health. (2019). Mental Il/ness. https://www.nimh.nih.gov/health/statistics/mental-illness.shtml

National Research Council \& Institute of Medicine. (2009). Preventing mental, emotional, and behavioral disorders among young people: Progress and possibilities. The National Academies Press.

Olfson, M. (2018). Recent trends in child, adolescent, and young adult mental, emotional, and behavioral health in the United States. Committee commission.

Palinkas, L. A., Aarons, G. A., Chorpita, B. F., Hoagwood, K., Landsverk, J., \& Weisz, J. R. (2009). Cultural exchange and the implementation of evidence-based practices: Two case studies. Research on Social Work Practice, 19(5), 602-612. https://doi.org/10.1177/1049731509335529

Pfitzer, M. W., Bockstette, V., \& Stamp, M. (2013). Innovating for shared value. Harvard Business Review, September 2013. https://hbr.org/2013/09/innovating-for-shared-value

Powell, B. J., Beidas, R. S., Lewis, C. C., Aarons, G. A., McMillen, J. C., Proctor, E. K., \& Mandell, D. S. (2017). Methods to improve the selection and tailoring of implementation strategies. The Journal of Behavioral Health Services \& Research, 44(2), 177-194. https://doi.org/10.1007/s11414-015$\underline{9475-6}$ 
Journal of Youth Development | http://jyd.pitt.edu/ | Vol. 15 Issue 3 DOI 10.5195/jyd.2020.950 MEB Development: Effective Implementation and Scale-Up

Powell, B. J., Beidas, R. S., Rubin, R. M., Stewart, R. E., Wolk, C. B., Matlin, S. L., Weaver, S., Hurford, M. O., Evans, A. C., Hadley, T. R., \& Mandell, D. S. (2016). Applying the policy ecology framework to Philadelphia's behavioral health transformation efforts. Administration and Policy in Mental Health, 43(6), 909-926. https://doi.org/10.1007/s10488-016-0733-6

Powell, B. J., McMillen, J. C., Proctor, E. K., Carpenter, C. R., Griffey, R. T., Bunger, A. C., Glass, J. E., \& York, J. L. (2012). A compilation of strategies for implementing clinical innovations in health and mental health. Medical Care Research and Review, 69(2), 123-157.

https://doi.org/10.1177/1077558711430690

Proctor, E., Silmere, H., Raghavan, R., Hovmand, P., Aarons, G., Bunger, A., Griffey, R., \& Hensley, M. (2011). Outcomes for implementation research: Conceptual distinctions, measurement challenges, and research agenda. Administration and Policy in Mental Health and Mental Health Services Research, 38(2), 65-76. https://doi.org/10.1007/s10488-010-0319-7

Proctor, E. K., Powell, B. J., \& McMillen, J. C. (2013). Implementation strategies: Recommendations for specifying and reporting. Implementation Science, 8(139). https://doi.org/10.1186/1748-5908-8$\underline{139}$

Resnicow, K., Soler, R., Braithwaite, R. L., Ahluwalia, J. S., \& Butler, J. (2000). Cultural sensitivity in substance use prevention. Journal of Community Psychology, 28(3), 271-290. https://doi.org/10.1002/(SICI)1520-6629(200005)28:3<271::AID-JCOP4>3.0.CO;2-I

Rivara, F. P., \& Johnston, B. (2013). Effective primary prevention programs in public health and their applicability to the prevention of child maltreatment. Child Welfare, 92(2), 119-139.

Romney, S., Israel, N., \& Zlatevski, D. (2014). Exploration-stage implementation variation: Its effect on the cost-effectiveness of an evidence-based parenting program. Journal of Psychology, 222(1), 37-48. https://doi.org/10.1027/2151-2604/a000164

Rushovich, B. R., Bartley, L. H., Steward, R. K., \& Bright, C. L. (2015). Technical assistance: A comparison between providers and recipients. Human Service Organizations: Management, Leadership \& Governance, 39(4), 362-379. https://doi.org/10.1080/23303131.2015.1052124

Sandler, I. N., Schoenfelder, E. N., Wolchik, S. A., \& MacKinnon, D. P. (2011). Long-term impact of prevention programs to promote effective parenting: Lasting effects but uncertain processes. Annual Review of Psychology, 62(1), 299-329.

\section{https://doi.org/10.1146/annurev.psych.121208.131619}

Schoenwald, S. K., \& Henggeler, S. W. (2003). Introductory comments. Cognitive and Behavioral Practice, 10(4), 275-277. https://doi.org/10.1016/S1077-7229(03)80045-7

Spoth, R., Clair, S., Greenberg, M., Redmond, C., \& Shin, C. (2007). Toward dissemination of evidencebased family interventions: Maintenance of community-based partnership recruitment results and associated factors. Journal of Family Psychology, 21(2), 137-146. https://doi.org/10.1037/0893$\underline{3200.21 .2 .137}$ 
Spoth, R., \& Greenberg, M. (2011). Impact challenges in community science-with-practice: Lessons from prosper on transformative practitioner-scientist partnerships and prevention infrastructure development. American Journal of Community Psychology, 48(1-2), 106-119. https://doi.org/10.1007/s10464-010-9417-7

Spoth, R., Redmond, C., Shin, C., Greenberg, M., Feinberg, M., \& Schainker, L. (2013). PROSPER community-university partnership delivery system effects on substance misuse through $61 / 2$ years past baseline from a cluster randomized controlled intervention trial. Preventive Medicine, 56(3-4), 190-196. https://doi.org/10.1016/j.ypmed.2012.12.013

Tabak, R. G., Khoong, E. C., Chambers, D. A., \& Brownson, R. C. (2012). Bridging research and practice: Models for dissemination and implementation research. American Journal of Preventive Medicine, 43(3), 337-350. https://doi.org/10.1016/j.amepre.2012.05.024

Tein, J. Y., Sandler, I. N., Ayers, T. S., \& Wolchik, S. A. (2006). Mediation of the effects of the family bereavement program on mental health problems of bereaved children and adolescents. Prevention Science, 72 ), 179-195. https://doi.org/10.1007/s11121-006-0037-2

Voorberg, W. H., Bekkers, V. J. J. M., \& Tummers, L. G. (2015). A systematic review of co-creation and co-production: Embarking on the social innovation journey. Public Management Review, 179), 1333-1357. https://doi.org/10.1080/14719037.2014.930505

Wakefield, M. A., Loken, B., \& Hornik, R. C. (2010). Use of mass media campaigns to change health behaviour. The Lancet, 376(9748), 1261-1271. https://doi.org/10.1016/S0140-6736(10)60809-4

Walker, S. C., Bumbarger, B. K., \& Phillippi, S. W. (2015). Achieving successful evidence-based practice implementation in juvenile justice: The importance of diagnostic and evaluative capacity. Evaluation and Program Planning, 52, 189-197. https://doi.org/10.1016/j.evalprogplan.2015.05.001

Waltz, T., Powell, B., Matthieu, M., Damschroder, L., Chinman, M., Smith, J., Proctor, E., \& Kirchner, J. (2015). Use of concept mapping to characterize relationships among implementation strategies and assess their feasibility and importance: Results from the Expert Recommendations for Implementing Change (ERIC) study. Implementation Science, 10(109). https://doi.org/10.1186/s13012-015-0295-0

Webster-Stratton, C. H., Reid, M. J., \& Marsenich, L. (2014). Improving therapist fidelity during implementation of evidence-based practices: Incredible years program. Psychiatric Services, 65(6), 789-795. https://doi.org/10.1176/appi.ps.201200177

West, G. R., Clapp, S. P., Averill, E. M., \& Cates, W., Jr. (2012). Defining and assessing evidence for the effectiveness of technical assistance in furthering global health. Global Public Health, 7 (9), 915930. https://doi.org/10.1080/17441692.2012.682075

Willging, C. E., Green, A. E., Gunderson, L., Chaffin, M., \& Aarons, G. A. (2015). From a "perfect storm" to "smooth sailing": Policymaker perspectives on implementation and sustainment of an 
Journal of Youth Development | http://jyd.pitt.edu/ | Vol. 15 Issue 3 DOI 10.5195/jyd.2020.950 MEB Development: Effective Implementation and Scale-Up

evidence-based practice in two states. Child Maltreatment, 20(1), 24-36. https://doi.org/10.1177/1077559514547384

Wingood, G. M., \& DiClemente, R. J. (2008). The ADAPT-ITT model: A novel method of adapting evidence-based HIV interventions. Journal of Acquired Immune Deficiency Syndromes, 47(Suppl. 1), S40-S46. https://doi.org/10.1097/QAI.0b013e3181605df1

Zakocs, R., \& Guckenburg, S. (2007). What coalition factors foster community capacity? Lessons learned from the fighting back initiative. Health Education \& Behavior, 34(2), 354-375. https://doi.org/10.1177/1090198106288492

Zakocs, R. C., \& Edwards, E. M. (2006). What explains community coalition effectiveness?: A review of the literature. American Journal of Preventive Medicine, 30(4), 351-361.

https://doi.org/10.1016/j.amepre.2005.12.004 